International Journal of Current Advanced Research

ISSN: O: 2319-6475, ISSN: P: 2319 - 6505, Impact Factor: SJIF: 5.995

Available Online at www.journalijcar.org

Volume 6; Issue 3; March 2017; Page No. 2590-2594

DOI: http://dx.doi.org/10.24327/ijcar.2017.2594.0053

Research Article

\title{
THE EFFECTIVENESS OF ENGLISH MOVIE SUBTITLES IN VOCABULARY LEARNING AMONG IRAQI KURDISTAN EFL LEARNERS: SORAN UNIVERSITY EFL LEARNERS AS AN EXAMPLE
}

\author{
Chiaye Khorsheed Faqe
}

Soran University- Faculty of Arts-English Department.

Rwandz Private Technical Institute - English Department

\section{A R T I C L E I N F O}

\section{Article History:}

Received $18^{\text {th }}$ December, 2016

Received in revised form $16^{\text {th }}$ January, 2017

Accepted $26^{\text {th }}$ February, 2017

Published online $28^{\text {th }}$ March, 2017

\section{Key words:}

Subtitles, movies, language learning, vocabulary learning, EFL learners.

\begin{abstract}
A B S T R A C T
The present study aims to investigate the role of English movie subtitles in vocabulary learning by EFL learners at Soran University. Using English movies with subtitles help EFL learners acquire more vocabularies and idioms. The participants were thirty one English department students, they were randomly selected. The participants were males and females and all of them had been learning English since primary school in Iraqi Kurdistan Region schools. And, the study is an attempt to motivate students to subtitles in improving their vocabulary while learning English as a foreign language. The results show that watching English movies with subtitles facilitates vocabulary learning and motivate students in acquiring new vocabularies, phrases, idioms and slangs.
\end{abstract}

Copyright $\bigcirc 2017$ Chiaye Khorsheed Faqe. This is an open access article distributed under the Creative Commons Attribution License, which permits unrestricted use, distribution, and reproduction in any medium, provided the original work is properly cited.

\section{INTRODUCTION}

With increasing access to audio - visual aids especially TV, English foreign language learners have found more opportunities to use audio-visual materials as effective tools in the process of learning English language. Those kinds of authentic materials are helpful for EFL learners motivate to learn more vocabularies and understanding the language better. Since the early 1970s, video materials have made its way into the EFL classrooms, promoting authenticity and diversity for student learning language through the use of popular foreign films via digital media. To (Gray, 1939, P.1) "Vocabulary is an essential means of interchanging ideas and of acquiring new experiences. Man's growth in ideas has always been accompanied by a corresponding expansion of his vocabulary".

Movies as audio-visual aid help students to improve their limited vocabulary, poor grammar and listening skill. Concerning vocabulary learning, subtitle movies play a crucial role in advancing the learners with new and up-to-date vocabularies and phrases. The combination sound and image remarkably motivate learners to achieve the learning process aims. Furthermore, watching subtitled movies improve EFL learners to learn those situations in which the new vocabularies are used.

*Corresponding author: Chiaye Khorsheed Faqe,

Soran University- Faculty of Arts-English Department. Rwandz Private Technical Institute - English Department
Also, acquiring other learning language goals like improving listening and speaking skills and well as improving pronunciation. Moreover, integrating subtitled movies inside the class or outside increase students' interest for the preferred language.

However, subtitled movies might bring the learners to realistic situations. Movies scenes lead you to explain the ideas and concepts of the scenes and help you to think and expect what might happen next. Besides, the combination of audio, video, contextual information will effectively adopt the learners to the new environment of language learning.

Watching subtitled movies can facilitate vocabulary building especially when it comes to English language learning. Most importantly, before having literature review, it is highly crucial to define subtitle. By subtitle, we mean the printed words at the bottom of the screen either in a foreign or same language showing those words and sentences by actors. (Zanon, 2006, P. 47) indicates that subtitles might be distinguished to the following types: 1. Bimodal subtitling (English dialogues to English subtitles). 2. Standard subtitling (English dialogues to learners' mother tongue language). 3. Reversed subtitling (dialogues form learners mother tongue language to English subtitles).

\section{LITERATURE REVIEW}

We cannot deny that audio visual aids have become a crucial part of people in general and learners in particular. When it comes to language learners, the audio visual aids are necessary rather than luxury; due to multimedia technology 
the process of learning has become effective. Video equipments and other modern pedagogical tools help language learners to improve their language properties an all aspects.

Most of previous studies emphasized that subtitled movies and captions facilitate the process of learning language and motivate students to realize the value of those pedagogical tools in improving their limited vocabulary and language skills.

According to (Danan, 2004, P. 67) audiovisual materials are useful tools for various reasons. The first reason is that "because they improve listening comprehension skills of second/foreign language learners; the second one "they facilitate language learning by helping learners visualize what they hear; and third, they increase language comprehension and lead to additional cognitive benefits, such as greater depth of processing".

Using videos and films as a learning tool received the attraction of researchers and even teachers in applying the tools successfully in a variety of educational environment. The first study about the effectiveness of subtitling was done by Price in which he conducted that subtitling resulted in comprehending a great deal of cultural background, linguistic aspects, and social behaviors (Price, 1983 as cited in Rokni and Ataee 2014, p.718).

Many scholars and researchers have conducted that videos with subtitles facilitate vocabulary acquisition. Koskenin et al, 1985 (as cited in Yuksel\& Tanriverdi, 2009, p. 1303) examined the effects of captioned videos on reading vocabulary. Based on the findings of their study, videos are substantially improved reading vocabulary knowledge nonnative English speakers. (Akbulut, 2007, p. 5) argued that "combining text with visuals is more effective in facilitating vocabulary learning than providing only definitions of words",

Several studies supported the use of film subtitles either in second language or foreign language. For this reason (Snyder and Colon, 1988. As cited in Rokni and Ataee 2014, p.718) indicated that those EFL learners who use audio visual aids are performed better in vocabulary learning and comprehension compared to those who don't expose the audio visual aids. While some of the opponents believe that using videos and films with subtitles is distracting and leads to slow down the learners' ability of listening comprehension skills.

However, (Canning-Wilson, C., \& Wallace, J. 2000) state that subtitled movies are significantly motivated language learners to consciously use new vocabularies and idioms. The learners have potential to vocabulary acquisition without being distracted. On the other hand (Zanon, 2006) showed opposed understanding toward the use of subtitles and claimed that it is still nuisance which leads to lessen the credibility of the movie. Sometimes subtitles might be tending to slow down the development of listening skills.

Movie subtitles have three types as (Zanon, 2006, p. 47) distinguished them to the following types: 1. Bimodal subtitling (English dialogues to English subtitles). 2. Standard subtitling (English dialogues to learners' mother tongue language). 3. Reversed subtitling (dialogues form learners mother tongue language to English subtitles). Among the three mentioned subtitles, bimodal subtitling is an appropriate type for EFL learners to follow because it helps the loaners to see and hear every single word.

However, there are still some opponents toward bimodal as well. For example (Etemadi 2012, as cited in Sabouri et al, 2015 , p.113) argued that even bimodal subtitle will not have any effect on vocabulary recognition, this is due to the fact that watching subtitled movies once might have no influence on vocabulary learning. On this account, students and learners can watch the movie more than once even twice and third so as to recognize vocabularies and learn new words, phrases and idioms.

According to (Koolstra and Beentjes, 1999 as cited in Rokni and Ataee, 2014, p.205) worked on some Dutch children toward vocabulary recognition and learning. They found that children acquired more English vocabulary from watching subtitled as compared to those who watched the same film without subtitles. As well as children with subtitled videos performed significantly better on a word recognition.

Some other researchers suggested that key words are significantly important rather than having the entire sentences. To (Guillory, 1998) keywords are beneficial especially for beginner furthermore; she found that beginning-level students would benefit more. She noted that keyword subtitling might be better for beginning-level learners because it may not impose as large of a cognitive load.

Some of the previous studies examined the role of movie subtitles in learning new vocabularies, because learning vocabulary is an essential part of learning a foreign language. One of the studies is carried by (Huang and Yang, 2012) emphasized that vocabulary learning is the source of learning language in authentic situations. They showed that extensive reading has been the main focus to assist learners in acquiring vocabulary incidentally.

Furthermore (Vanderplank, 1988, p. 277) highlighted that movie subtitles can bring benefits to hard of hearing learners. Infact, research findings show that learners use subtitles as a support for listening comprehension and for finding new words.

It needs to be admitted that (Bean \& Wilson, 1989, as cited in Peng, 2102, p.15) showed that non-native speaking students and learners have positive attitude toward captioning and increased vocabularies with subtitled movie. They concluded that students with subtitled materials showed remarkable improvement in vocabulary acquisition, word recognition, and listening comprehension.

All things considered, subtitled videos, movies and films are a rich source in communicative language in use. Languages are changeable, not fixed at all. Every day new things come languages and the best way to reflect this is through movies, $\mathrm{TV}$, and multimedia in general. Movie subtitles give language learners more motivations and comforts, as well as the production of new terms, words, phrases and idioms.

\section{Statement of the Problem}

To resolve the impacts of using subtitles in vocabulary acquisition while watching subtitled movies, the present study seeks to find out" How effective is English movie with subtitles help the improvement of vocabulary by Soran University EFL learners in learning English vocabulary"? 


\section{METHODOLOGY}

\section{Participants}

The participants of the present study were 31 Kurdish EFL learners of English department at Soran University. The participants were (14 males) and (17 females). Infact, all participants were Kurdish students and their mother tongue language was Kurdish language. The participants were from two classes and their age ranges were between (19-22). All participants were at the same level of vocabulary knowledge based on Michigan test of English Language Proficiency. The participants were randomly selected.

\section{Instruments}

\section{Proficiency Test}

1. At the beginning of study, the researcher was given the participants Michigan test of English Language Proficiency to assess the participants' proficiency level and make the participants homogenized.

2. The instrument that was used to gather data was a Likert- scale questionnaire. It was a self made instrument devise. The mechanisms and requirements of the questionnaire as well as the nature of the study were explained to respondents. A close-ended questionnaire was developed to determine the participants' attitude toward watching movies with subtitles and without subtitles in vocabulary learning. The researcher used test and retest method to get reliability for both scales of questionnaires.

\section{Selecting movie}

An English animation movie named Kung Fu Panda Holiday was used in the study which is an animation movie. The movie was a dream work and "PO" as a main character tried to host winter holiday feast but he found hard to meet his friends' expectations. It was about 21 minutes long. The purpose of selecting this movie is the suitability in vocabulary recognition based on the variety of vocabulary knowledge.

\section{Procedure}

In order to conduct the present study, the participants were gathered in a room with multimedia facilities. To begin with, all the participants watched 21 minutes movie without subtitle, after that; the participants were given a questionnaire related to the selected movie. This treatment was done to find out the participants' improvement in vocabulary learning while they watch the movie without subtitle. And then the participants watched the same movie but with bimodal subtitle, and another questionnaire distributed to find out the participants attitude towards watching movies with subtitles in vocabulary achievement.

\section{RESULTS OF THE STUDY}

\section{Part One: Students' perceptions toward watching movie with and without subtitle.}

Table one illustrates that providing subtitles while watching English movies is an effective tool in achieving more vocabularies, as compared to watching the same movies without subtitle. The mean of students while watching the movie without subtitle is (31.00), but when they watched the same movie with subtitles the mean changed to (35.87) which indicate that providing subtitles have an effective impact on students' achievement of more vocabularies.

\section{Table One}

\begin{tabular}{lccccccc}
\hline & N & Mean & $\begin{array}{c}\text { St. } \\
\text { Deviation }\end{array}$ & $\begin{array}{c}\text { Degree of } \\
\text { Freedom }\end{array}$ & T table & T & Sig2-tailed \\
\hline $\begin{array}{c}\text { Without } \\
\text { subtitle } \\
\text { With }\end{array}$ & 31 & 31.00 & 4.54 & & & & \\
subtitle & 31 & 35.87 & 3.87 & 30 & 2.042 & -4.17 & Significant \\
\hline
\end{tabular}

The analysis of the questionnaire data revealed that Kurdish EFL learners have positive attitude toward using subtitled movies in the process of language learning and vocabulary recognition in particular. The difference here between watching movie with subtitle and without subtitle is significant. To get the above results, the researcher used paired sample $\mathrm{T}$ test.

\section{Part Two: Gender differences without subtitle.}

Table Two

\begin{tabular}{ccccccccc}
\hline Gender & N & Mean & $\begin{array}{c}\text { St. } \\
\text { Deviation }\end{array}$ & $\begin{array}{c}\text { Degree of } \\
\text { freedom }\end{array}$ & T table & T & Sig-2tailed \\
\hline $\begin{array}{c}\text { Male } \\
14\end{array}$ & 29.93 & 3.97 & 29 & 2.045 & -1.18 & No significant \\
Female & 17 & 31.88 & 4.98 & & & &
\end{tabular}

Table two illustrates that females are better comprehended the movie without subtitles as compared to males. The mean degree of females is (31.88) which more than (29.93) by males. This is a remarkable finding which indicates that females are faster than males in comprehending the content and vocabularies of the watched movie, which is clear evidence that subtitles might be tending to slow down the development of listening skills by males.

The differences are not too significance because it is not big. To get the reliable results here, the researcher used independent sample $\mathrm{t}$ test for both gender differences in watching movies with and without subtitles.

\section{Part Three: Gender differences with subtitle}

Table Three

\begin{tabular}{ccccccccc}
\hline Gender & N & Mean & $\begin{array}{c}\text { St. } \\
\text { Deviation }\end{array}$ & $\begin{array}{c}\text { Degree of } \\
\text { Freedom }\end{array}$ & $\begin{array}{c}\mathbf{T} \\
\text { table }\end{array}$ & T & Sig-2tailed \\
\hline $\begin{array}{c}\text { Male } \\
\text { Female }\end{array}$ & 14 & 37 & 1.3 & 29 & 2.045 & 1.5 & $\begin{array}{c}\text { No } \\
\text { significant }\end{array}$ \\
\hline
\end{tabular}

Table three indicates that male students are better comprehended as compared to female students. The mean degree by male students is (37) as compared to female mean degree (34.94).It can be clearly proven that male students are more quicker than female students in reading the bimodal subtitles of the movie and acquired more words and vocabularies.

\section{DISCUSSION}

The present study attempted to investigate the impact of movie subtitles in vocabulary learning among Soran University EFL learners. The answer to the research question, concerning the effectiveness of subtitled movies toward vocabulary improvement. The analysis of the questionnaire data revealed that Kurdish EFL learners have positive attitude 
toward using subtitled movies in the process of language learning and vocabulary recognition in particular. Based on the results of previous studies and the present one, we come to a significant result in which subtitles are beneficial in improving vocabulary learning, especially bimodal subtitles.

Furthermore, regarding the comparison of participants' attitude between watching movies with subtitles and without, the analysis of present study revealed that participants acquired more words while watching the movie with subtitles. The findings of current study were accordance with previous studies, such as (Mitter and Mcqueen, 2009, as cited in Mousavi and Gholami, 2014, p. 1280) revealed that "revealed that native-language subtitles appear to create lexical interference, but foreign-language subtitles assist speech learning by indicating which words (and hence sounds) are being spoken".

The participants also commented that, at the beginning their learning time it was difficult for to understand every single word on the movie, but with the help of bimodal subtitles they could manage ability to learn new vocabularies included words, idioms, and slangs. ( Putra, 2014) experienced in his study and found that "Two types of subtitling, bimodal and standard subtitling, were given to the respondents, and it appeared that after watching the movie more than once and used those two different types of subtitling, the respondents gained more vocabulary effectively".

The study findings revealed that most of the participants believed that using movie subtitles is a better way to improve English language vocabualry as a foreign language and better acquainted with their culture. The participants made a significant improvement in their vocabulary knowledge after watching the movie with subtitle as compared to viewing the movie without subtitle. (Paivio, 1971, as cited in Harji et al, 2010 , p. 38) proposed that "when pictures are added to the meaning, the number of signals connected with the message increases. Viewers then will be more probable to keep the message in mind".

Due to the results of the current study, the researcher supports viewing movies with subtitles not only for vocabulary improvement, but also learners may improve their spelling, word recognition capability, pronunciation of new words and words they have already learned, understanding of spoken language through idioms and slangs, and culture awareness as well. The findings of current study might accord with (Vanderplank, 1988, p. 272-273) stating that "subtitles might have potential value in helping the language acquisition process by providing learners with the key to massive quantities of authentic and comprehensible input".

It can be clearly seen that watching subtitled movies could have effective impacts on student's perception toward viewing English movies with subtitles. Some of the students mentioned that they need to watch the movie more than once; otherwise the process might be a kind of disturbing and confusing.

Moreover, watching movies more than once can improve the learners' skills of listening and reading as well as gaining more vocabularies, idioms, and slangs simultaneously. Most of previous researches indicated that subtitled movies could bridge the gap between language skills and vocabulary knowledge. For further studies, it is desirable for researchers to investigate the role of viewing English movies either with subtitles or without in learners' listening and speaking performances, also the degree of motivation toward language learning in general.

\section{Recommendations}

One of the recommendations on helping Kurdish EFL learners in acquiring more vocabularies is to integrate technology devices in their learning environment. Kurdish EFL learners in Iraqi Kurdistan region need more supports to adopt with foreign culture and this can be done through watching English movies to familiarize with the culture and those new slangs and idioms that daily come to English language.

Furthermore, more vocabularies might be watching movies with bimodal and standard subtitles at least two days a week in a multimedia room with absolute facilities. Because changing the teaching strategy might conduct as an effective teaching environment and producing more learners with high argumentations and critical thinkers while they watch the dialogue and argumentations on movies.

English language teachers in Iraqi Kurdistan region need to consider providing Kurdish EFL learners with watching English films in their spare time and friendly atmosphere should be maintained to gain more language skills and vocabulary recognition during the time of watching movies. Kurdish researchers might develop other projects seeking the influences of movie subtitles on other components of language, such as listening comprehension, reading and pronunciation abilities.

\section{References}

Akbulut, Y. (2007). Variables predicting foreign language reading comprehension and vocabulary acquisition in a linear hypermedia environment. . The Turkish Online Journal of Educational Technology- TOJET, 6(1), article 5. Retrieved January 1, 2009, from http://www.tojet.net/articles/615.htm

Canning- Wilson, C., \& Wallace, J. (2000). Practical aspects of using video in the foreign language classroom. The internet TESL Journal, 6, 31-36.

Danan, M. (2004). Captioning and subtitling: Undervalued language learning strategies. Meta, 49, 67-77.

Gray, W. \& Eleanor, H. (1939). The development of meaning vocabularies in reading. Chicago: University of Chicago Press.

Guillory, H.G. (1998). The effects of key word captions to authentic French video in foreign language instruction. CALICO Journal, 15(1-3), 89-108.

Harji, M. \& et al. (2010). The Effect of Viewing Subtitled Videos on Vocabulary Learning. Journal of College Teaching \& Learning, 7, 27-42.

Huang, B. G., \& Yang, J. C. (2012). A Multiplayer Online Role-Playing Game for Incidental Vocabulary Learning. In Proceedings of the 20th International Conference on Computers in Education (ICCE 2012). Singapore.

Koskenin, P., Wilson, R., Jensema, C. (1985). Closedcaptioned television: A new tool for reading instruction. Reading World, 24, 1-7.

Mousavi, F \& Gholami, J. (2014). Effects of Watching Flash Stories with or without Subtitle and Reading Subtitles on Incidental Vocabulary Acquisition. Procedia - Social and Behavioral Sciences 98 (2014) 1273 - 1281. 
Peng, L. (2012). The Impacts of DVD Films on EFL Learners Listening Comprehension. Published M.A thesis in Education and Applied Linguistics at MING CHUAN UNIVERSITY.

Putra, P. (2014). Learning Vocabulary Using English Movie with Subtitles in Smak Santo Yoseph. Online Journal of Humanis.

Rokni, J \& Ataee, A. (2014). The Effect of Movie Subtitles on EFL Learners' Oral Performance. International Journal of English language, Literature and Humanities. Volume 1 Issue V Feb 2014.201-215.
Sabouri, H et al. (2015). The Impact of Watching English Subtitled Movies in Vocabulary Learning in Different Genders of Iranian EFL Learners. International Journal on Studies in English Language and Literature, Volume 3, Issue 2, February 2015, PP 110-125.

Vanderplank, R. (1988). "The value of teletext sub-titling in language learning", in ELT journal, 42: 272-281.

Yuksel, d. \& Tanriverdi, b. (2009) Effects Of Watching Captioned Movie Clip On Vocabulary Development Of EFL Learners. The Turkish Online Journal of Educational Technology - TOJET April 2009 ISSN: 1303-6521 volume 8 Issue 2 Article 4

Zanon, N. (2006). Using Subtitles to Enhance Foreign Language Learning. Porta Linguariam, 6, 41-52.

\section{Please cite this article in press as:}

Chiaye Khorsheed Faqe (2017), 'The Effectiveness Of English Movie Subtitles In Vocabulary Learning Among Iraqi Kurdistan Efl Learners: Soran University Efl Learners As An Example', International Journal of Current Advanced Research, 6(3), pp. 2590-2594. http://dx.doi.org/10.24327/ijcar.2017. 2594.0053 